\title{
GARANTIA DO DIREITO AO AMBIENTE ATRA VÉS DA PROTEÇÃO DO DIREITO À HABITAÇÃO NO CONSELHO DA EUROPA
}

\author{
Alexandra Aragão \\ Universidade de Coimbra, Portugal \\ aaragao@fd.uc.pt
}

\begin{abstract}
RESUMO: O presente artigo estuda as formas de proteção judicial das condições ambientais de vida através do direito humano à habitação, em intenso diálogo com a jurisprudência do Tribunal Europeu dos Direitos do Homem, principalmente ao considerar a ausência de norma expressa que assegure a proteção do direito ao ambiente na Convenção Europeia dos Direitos do Homem e Liberdades Fundamentais. Paralelamente, evidencia-se o papel fundamental do Tribunal Europeu para a evolução da matéria, tendo em vista que, por meio de seu esforço jurisprudencial, empenha-se em garantir tal direito mesmo que indiretamente. A metodologia utilizada será indutiva, com uma análise jurisprudencial do Tribunal Europeu. Concluem-se duas possíveis vias de evolução jurisprudencial: a primeira é a ampliação das formas de degradação ambiental considerada relevante para efeito de proteção judicial; a segunda decorre de uma nova perspetiva sobre a opção de realojamento das vítimas.
\end{abstract}

PALAVRAS-CHAVE: Direito ao ambiente; Direito à habitação; Conselho da Europa.

\section{Guarantee of the right to the environment through the protection of the right to housing in the council of europe}

\begin{abstract}
This article studies the forms of judicial protection of environmental living conditions through the human right to housing, in intense dialogue with the jurisprudence of the European Court of Human Rights, especially when considering the absence of an express rule that ensures the protection of the right to environment in the European Convention on Human Rights and Fundamental Freedoms. At the same time, the fundamental role of the European Court for the evolution of the matter is evidenced, considering that, through its jurisprudential effort, it strives to guarantee such right even if indirectly. The methodology used will be inductive, with a case law analysis by the European Court. Two possible paths of jurisprudential evolution are concluded: the first is the expansion of forms of environmental degradation considered relevant for the purpose of judicial protection; the second stems from a new perspective on the option of relocating victims.
\end{abstract}

KEYWORDS: Right to environment; Right to housing; Council of Europe.

\section{INTRODUÇÃO}

No contexto do Conselho da Europa, a particularidade da proteção jurídica do Direito humano à habitação decorre da interpretação atualista, aceite pelo Tribunal Europeu dos Direitos do Homem desde os anos 90, que amplia do âmbito de proteção da norma para cobrir também a qualidade do ambiente no interior da habitação. Assim, na ausência de norma expressa que assegure a proteção autónoma do Direito do ambiente na Convenção Europeia dos Direitos do Homem e Liberdades Fundamentais, a figura das ingerências ambientais arbitrárias no direito a 
usufruir o domicílio foi a solução jurídica ${ }^{1}$ encontrada para manter a utilidade e a atualidade da Convenção enquanto "instrumento vivo"2. Nas palavras do Conselho da Europa, esta evolução justifica-se porque "ao desempenhar a sua tarefa de interpretar a Convenção, o Tribunal adota uma abordagem evolutiva. Portanto, a interpretação dos direitos e liberdades não é fixa, mas pode levar em conta o contexto social e as mudanças na sociedade" 3 .

À vista disso, o objetivo do presente estudo é compreender as formas de proteção judicial das condições ambientais de vida por meio do direito à habitação, em diálogo intenso com a jurisprudência do Tribunal Europeu dos Direitos do Homem, principalmente ao considerar a inexistência de norma expressa que assegure a proteção do direito humano ao ambiente na Convenção Europeia dos Direitos do Homem e Liberdades Fundamentais.

Com efeito, desde há décadas que o direito humano ao ambiente deveria ter beneficiado de reconhecimento convencional e proteção jurídica internacional ${ }^{4}$ no âmbito da Convenção dos Direitos do Homem. A primeira recomendação formal da Assembleia Parlamentar do Conselho da Europa sobre a inclusão do direito humano a um ambiente "saudável e viável" na Convenção,

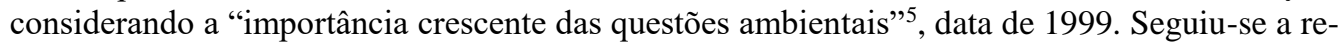
comendação de 2003, sobre "ambiente e direitos humanos", onde a Assembleia afirmou a importância de um ambiente "saudável, viável e decente" e recomendou aos Estados que "protejam adequadamente a vida, a saúde, a família e a intimidade da vida privada, a integridade física e a propriedade das pessoas, nos termos dos artigos 2, 3 e 8 da Convenção, e do artigo 1 do seu Protocolo Adicional, tendo particularmente em atenção a necessidade de proteção ambiental"6.

Praticamente chegados à segunda década do século XXI, mais de 20 anos passados sobre a primeira constatação formal da lacuna ambiental na Convenção, a recomendada inclusão do novo direito humano ainda não aconteceu. É deste modo que, a assumida insuficiência da Convenção, tem sido colmatada pelo Tribunal Europeu dos Direitos do Homem utilizando os meios de proteção jurídica indireta atualmente ao seu dispor, que vão desde a defesa do direito à vida, até à proteção do direito de propriedade; desde a exigência do direito à informação, até à garantia de acesso à justiça... passando, naturalmente, pelo direito à habitação. O esforço judicial para ultrapassar, através de uma jurisprudência que leva a cabo uma "interpretação dinâmica e de uma atualização evolutiva"”, a propalada ausência de proteção autónoma, demonstra à outrance o

1 Dinah Shelton explica como se desenvolve o processo de utilização do direito ambiental para dar substância à proteção do direito ao ambiente como direito humano («Developing Substantive Environmental Rights», 1 Journal of Human Rights \& Environment, March 2010, p. 89-120.

2 Encontramos a expressão "instrumento vivo" na opinião parcialmente dissidente dos juízes Costa, Ress, Türmen, Zupančič e Steiner no Caso Hatton de 2003: "Sendo a Convenção um instrumento vivo, a disposição foi gradualmente interpretada para incluir também os direitos ambientais. Existem limites quanto ao tipo de problemas ambientais poluição no sentido mais amplo da palavra - que as pessoas terão que aceitar antes de esses problemas levarem a uma violação do Artigo 8". Fora da área ambiental, a chamada "doutrina do instrumento vivo" foi amplamente discutida no caso Magyar Helsinki Bizottsag v. Hungria, de 2016, onde (a propósito da liberdade de expressão de uma organização não governamental que pretende aceder a informação de interesse público) a "doutrina" é invocada pelas partes e amplamente discutida pelos Juízes Raimondi e Sicilianos, na sua opinião concorrente, afirmando que o objetivo dessa doutrina é adaptar o tratado às condições atuais (16.) e chegando a exclamar que ela é "condição sine qua non da sobrevivência da Convenção!” (6.).

3 Manual on Human Rights and the Environment, Council of Europe, Strasbourg, 2012, página 31.

4 Susan Glazebrook, juíza no Tribunal de recurso da Nova Zelândia, analisa, um por um, doze argumentos contra a existência de um direito humano a um ambiente de qualidade ("Human Rights and the environment", Victoria University of Wellington Law Review, vol. 40 n. ${ }^{\circ} 1$ June 2009, p. 293).

5 Ponto 8 da Recomendação 1431 (1999), intitulada "Future action to be taken by the Council of Europe in the field of environment protection"

6 Ponto 1 da Recomendação 1614 (2003) intitulada "Environment and human rights".

7 A expressão é utilizada pelo Juiz Zagrebelsky na fundamentação da sua opinião dissidente no caso Kyrtatos contra Grécia (2003). 
papel fundamental do Tribunal Europeu na garantia das condições ambientais de vida através de outros direitos humanos. Destes, estudaremos apenas o direito à habitação.

$\mathrm{Na}$ linha da opinião convergente do Juiz Zupancic, no acórdão Bacila c. Roménia, de 2010, sublinhamos que não pode a tutela jurídica de situações flagrantemente carecidas de proteção ficar dependente de enquadramentos conceptuais por vezes afastados da realidade e desatualizados, quando se exige de um órgão judicial com a importância do Tribunal Europeu dos Direitos do Homem, que profira decisões que adiram à realidade, que produzam efeitos úteis e assegurem uma proteção efetiva ${ }^{8}$.

Finalmente, a mobilização do artigo $8^{\circ}$ para causas ambientais ocorre, pela primeira vez, no caso Lopez Ostra c. Espanha de 1994, 40 anos após a aprovação da Convenção, sem necessidade de qualquer alteração introduzida na Convenção ou em instrumentos jurídicos conexos.

O que mudou então, que permitiu uma releitura da norma? Simplesmente, a partir da segunda metade do século XX, a colisão de dois mundos $^{9}$ — a sociedade e a ecologia — tornouse evidente. As primaveras tornaram-se ainda mais silenciosas ${ }^{10}$ e a vulnerabilidade humana face às dramáticas transformações ambientais tornou-se inegável. $\mathrm{O}$ direito de destruir ${ }^{11}$ tinha acabado e a natureza não podia continuar à margem da lei ${ }^{12}$.

Deste modo, surge um novo paradigma socio-ambiental, que vem com novas exigências jurídico-ambientais. O uso emancipatório do Direito ${ }^{13}$ confere proteção jurídica às novas vítimas do desenvolvimento - depois dos escravos do período colonial, depois dos operários da revolução industrial — vítimas impotentes perante um abismal desequilíbrio de armas, reféns da esperança de uma vida melhor, aprisionadas entre o apoio dos Estados aos investimentos produtivos criadores de emprego e desenvolvimento económico, e os impactes ambientais sofridos na pele, na sua habitação ${ }^{14}$, e sentidos na intimidade da vida privada e familiar.

Na presente pesquisa, adotando-se uma abordagem metodológica indutiva, procede-se a uma análise jurisprudencial do Tribunal Europeu relacionada à proteção das condições ambientais de vida através do direito à habitação. $\mathrm{O}$ desenvolvimento organiza-se essencialmente em três partes: na primeira, de caráter mais descritivo, é feito um exame dos cenários estilizados da violação ambiental do direito à habitação a partir dos posicionamentos dos Estados membros do Conselho da Europa, em seguida é feita uma exposição e análise do sistema de proteção jurisprudencial instituído pelo Tribunal Europeu dos Direitos do Homem e, por fim, é discutido o futuro do direito à habitação à luz da jurisprudência destacada.

8 A opinião concordante do Juiz Zupancic no caso Bacila contra Roménia, de 2010, vem na sequência do seu voto de vencido no caso Tatar contra Roménia, de 2009.

9 A expressão é uma alusão à obra de Klaus Bosselmann, When two worlds collide: society and ecology, RSVP Publishing Company Limited, 1995.

${ }^{10}$ Rachel Carson, Silent Spring, Houghton Mifflin, 1962.

${ }^{11}$ Da obra clássica de Martine Rémond-Gouilloud, Du droit de détruire : éssai sur le droit de l'environnement, Presses Universitaires de France, 1989.

12 A expressão corresponde à tradução portuguesa da obra emblemática de François Ost, La Nature hors la Loi. François Ost, A Natureza à Margem da Lei. A ecologia à prova do Direito, Piaget, 1998.

${ }^{13}$ Boaventura de Sousa Santos, "Poderá o Direito ser emancipatório?" Revista Crítica de Ciências Sociais, n. ${ }^{\circ} 65$, maio de 2003, 3-37.

14 A proteção da habitação é cada vez mais uma aspiração dos cidadãos que propuseram uma iniciativa de cidadania intitulada "habitação para todos", que visa "melhorar as condições-quadro jurídicas e financeiras para facilitar o acesso à habitação para todos na Europa" e que foi aprovada para recolha de assinaturas pela Decisão 2019/435 da Comissão Europeia, de 12 de março de 2019. 


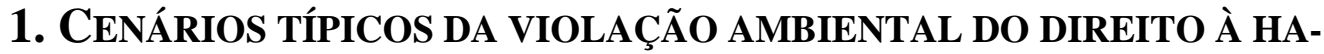 BITAÇÃO}

Uma análise das respostas dos Estados membros do Conselho da Europa às queixas, reclamações, impugnações e recursos judiciais e extrajudiciais dos cidadãos, durante a fase interna do conflito, antes do recurso ao Tribunal Europeu, permite reconduzir essas respostas das autoridades nacionais, tipicamente, a quatro cenários estilizados. Estes cenários, que caracterizaremos sumariamente em seguida, não dependem da posição em que o Estado está, relativamente à atividade nociva — responsável com controlo direto da atividade e deveres negativos de proteção, ou entidade com poderes de supervisão da atividade e deveres positivos de fiscalização e sanção- mas permitem-nos ter uma compreensão das formas de desproteção do direito humano à habitação.

Proteção ineficaz. Confrontado com a alegada violação de direitos fundamentais dos cidadãos, o Estado adota medidas puramente simbólicas que, na prática, configuram um abandono do cidadão a si próprio, uma vez que não dão uma resposta minimamente aceitável às queixas apresentadas. Também se enquadram neste cenário os casos em que, perante os protestos dos cidadãos, o Estado adota medidas aparentemente fortes, mas ineficazes, que alegadamente não conduzem a nenhuma alteração substancial do status quo lesivo dos direitos humanos. Ilustrativamente será o caso Fadyeva c. Rússia em que o cidadão é posto, durante anos a fio, na lista de espera para receber uma casa nova. É também o caso da aplicação de medidas sancionatórias de caráter penal contra responsáveis da empresa (caso Bacila c. Roménia, 2010) sabendo que, em contexto empresarial, podem não conduzir a qualquer alteração de práticas, nomeadamente se houver alteração da titularidade da empresa (como no caso Cordella c. Itália, 2019). Outro exemplo pode ser a alteração do horário de encerramento dos estabelecimentos ruidosos de recreação noturna, sabendo-se que, mesmo depois do encerramento, os clientes dos estabelecimentos prosseguem as atividades ruidosas no exterior (caso Mileva c. Bulgária, 2011). Por fim, no caso Dees c. Hungria de 2011, inúmeras medidas para controlar o ruído do trânsito numa estrada foram adotadas, mas nenhuma foi verdadeiramente eficaz.

Proteção incoerente e assistemática. Reagindo às sucessivas queixas, reclamações e recursos, a atuação do Estado caracteriza-se por uma profunda incoerência. Diferentes órgãos administrativos que proferem decisões contraditórias, quando os tribunais invalidam planos e atos administrativos, os tribunais superiores revogam as decisões dos inferiores, e até, mais grave de tudo, a administração desrespeita decisões judiciais. As contradições jurídicas mencionadas podem assumir um caráter de normalidade democrática como acontece no controlo judicial de atos administrativos ou nos recursos judiciais (caso Bor c. Hungria, 2003), ou de patologia democrática, como no caso do incumprimento ou desrespeito frontal das decisões judiciais (caso Kyrtatos c. Grécia, 2003; Apanasewicz c. Polónia, 2011; Dzemyuk c. Ucrânia 2014). Assim, a incoerência jurídica pode ser legal ou ilegal, mas o efeito prático é sempre o mesmo: a desproteção das vítimas que não conseguem, no plano interno, obter uma tutela jurídica definitiva, e sofrem durante anos ou décadas, violações do direito à habitação (casos Moreno Gomez c. Espanha, 2005; Giacomelli c. Itália, 2007; ou Furlepa c. Polónia, 2008).

Não proteção fundamentada. Dando sequência às exposições dos cidadãos, o Estado propõe-se levar a cabo estudos aprofundados, com ou sem envolvimento dos próprios cidadãos, que considera suficientes para concluir, fundamentadamente, que não há qualquer perturbação do direito protegido ou a perturbação não é significativa, pelo que não há violação de direitos humanos (Ruano Morcuende c. Espanha, 2005; Borysiewicz c. Polónia, 2008; Ivan Atanasov c. Bulgária, 2011; Pino Manzano c. Espanha, 2012). Pode também acontecer que o Estado considere que a perturbação existe e é significativa, mas ela é justificada, na medida em que a atividade 
tem enquadramento legal e responde a valores democráticos mais elevados. Assim se passou no primeiro caso do aeroporto de Heathrow (Powell c. Reino Unido, 1990), no caso das eólicas suecas (Fagerskiold c. Suécia, 2008), no caso do fogo de artifício maltês (Zammit c. Malta, 2012), ou no caso do aeroporto francês (Flamenbeaum c. França, 2013).

Proteção gradual. Em resposta às reivindicações apresentadas, o Estado procede, mais uma vez com ou sem envolvimento do próprio cidadão, aos estudos considerados necessários, às análises tidas por adequadas e vai introduzindo alterações, pela via legislativa, administrativa ou judicial, nas condições de funcionamento da atividade, nas condições de habitação da vítima, ou em ambas, de forma a reduzir os impactes. Ao largo de um tempo, muitas vezes longo, o Estado vai apertando o regime jurídico que enquadra a atividade em causa. Desta forma vai respondendo, por iterações sucessivas, às recorrentes queixas dos cidadãos, o que tem como resultado uma redução objetiva, ainda que considerada insuficiente pelas vítimas, das perturbações sentidas na habitação. Foi assim no caso Hatton c. Reino Unido 2003, relativamente ao aeroporto de Heathrow, ou no caso Greenpeace c. Alemanha, 2009, relativamente a um cruzamento rodoviário.

\section{LIÇÕES A TIRAR DA JURISPRUDÊNCIA DO TRIBUNAL EUROPEU}

Numa leitura transversal ${ }^{15}$, que pontos comuns encontramos no sistema de proteção jurisprudencial instituído, que nos permita tirar lições sobre o futuro da proteção internacional do direito humano ao ambiente?

\subsection{Lições a tirar quanto à relação entre o número de recorrentes e o número de afetados}

Em casos como Kolyadenko c. Rússia, de 2012, temos seis recorrentes e mais de 5.000 moradores afetados pelas inundações súbitas; no caso Fadeyeva c. Rússia, de 2005, temos um recorrente e 60000 trabalhadores que residem dentro da zona de proteção sanitária da fábrica; no caso Cordella c. Itália, de 2019, temos 180 recorrentes e 200.000 habitantes que residem em zonas classificadas como de "alto risco ambiental".

Nestes casos é bem visível a importância de existirem mecanismos de flexibilização da legitimidade processual ativa, como o direito de ação popular, para facilitar o acesso à justiça não em nome próprio, mas em nome de todos, baseado num direito difuso a um ambiente são. Refletindo o espírito do tempo ${ }^{16}$, a questão da ação popular é frontalmente discutida no caso Cordella c. Itália, de 2019, ainda que, tanto o Estado como o Tribunal tenham afastado a exigibilidade, à luz do sistema instituído, da actio popularis.

\footnotetext{
${ }^{15}$ Muitas outras grelhas de leitura da jurisprudência seriam possíveis. Uma das mais promissoras seria uma leitura à luz da utilização dos princípios estruturantes do direito do ambiente, máxime, dos princípios substantivos da precaução, da prevenção, ou do poluidor pagador, e adjetivos do acesso à informação, participação e acesso à justiça. A título de exemplo veja-se Ole Pedersen, "Environmental principles and the European Court of Human Rights" in Ludwig Kramer and Emanuela Orlando (eds), Principles of Environmental Law, Elgar Encyclopedia of Environmental Law (Edward Elgar) vol VI, 2018, p. 578-586.

16 Alexandra Aragão e Ana Celeste Carvalho, "Taking access to justice seriously: diffuse interests and actio popularis. Why not?" in: ELNI Review, Environmental Law Network International, n 2/2017, p. 42-48.
} 


\subsection{Lições a tirar quanto à duração da infração até à prolação do acórdão do Tribunal Europeu}

Na maior parte dos casos, a clarificação judicial da situação de degradação tarda anos, ou mesmo décadas ${ }^{17}$. Os casos de poluição industrial são os que ultrapassam todos os limites, mas mesmo noutros casos, os números são impressionantes. Nas atividades industriais, temos os casos Fadeyeva c. Rússia, de 2005, com a indústria de aço a laborar desde a década de 60; no caso Bacila c. Roménia, de 2010, a siderurgia funciona desde a década de 30; no caso Cordella c. Itália, de 2019, também uma siderurgia, em atividade desde 1965. Noutros casos, como Moreno Gomez c. Espanha, de 2005, os primeiros bares e discotecas foram licenciados em 1974; no caso Giacomelli c. Itália, de 2007, a gestão de resíduos começou em 1950; no caso Di Sarno c. Itália, 2012, a região de Nápoles decretou o estado de emergência em virtude dos problemas de gestão de resíduos durante 15 anos, entre 1994 e 2009.

Estes casos demonstram bem a necessidade de mecanismos mais céleres, ao nível interno, que permitam, de forma expedita, proteger com eficácia direitos de enorme importância pessoal e social, sem ter de aguardar décadas.

\subsection{Lições a tirar quanto ao tipo de atividade em causa}

Entre os muitos casos em que o Tribunal Europeu declarou a violação do artigo $8^{\circ}$, aqueles que revelam contornos mais chocantes, pela gravidade e pela duração dos impactos das atividades nocivas, são os que envolvem quatro tipos de atividades: atividades extrativas de mineração, atividades industriais de transformação, atividades de transporte intensivo e atividades ruidosas de diversão noturna.

Estes casos provam que a forma de prosseguir certas atividades, pelos incómodos que causam e pela gravidade das consequências que comportam para a qualidade de vida dos moradores, deveria ser repensada, com vista a evitar poluição tão intensa, degradação tão grave da qualidade ambiental e perda tão significativa de qualidade de vida. Sempre que possível, a solução ideal deveria passar pela proibição absoluta e urgente de tecnologias obsoletas ${ }^{18}$, suscetíveis de ser substituídas com vantagem pelas "melhores tecnologias disponíveis" exigidas pela legislação europeia ${ }^{19}$. Noutros casos, deveria aumentar-se significativamente o afastamento em relação a áreas residenciais; por fim, quando nenhuma destas soluções seja viável, deveria ponderarse a renúncia às atividades em causa, repensando, numa sociedade em transição ecológica, as necessidades que esses produtos, bens ou serviços visam satisfazer.

\footnotetext{
${ }^{17}$ Em muitos destes casos a violação do artigo $8^{\circ}$ surge associada à violação do artigo $6^{\circ}$ da Convenção Europeia dos Direitos do Homem, sobre direito de acesso à justiça, em virtude da morosidade judicial dos processos internos.

${ }^{18}$ O argumento utilizado pelo Governo Romeno no caso Tatar contra Roménia, de 2009, que alega que há 90 países no mundo, três dos quais situados na Europa, que ainda usam o cianeto na exploração mineral é revelador de uma inércia leviana e inadmissível.

19 Artigo 3 n. ${ }^{\circ} 10$ e 19 da Diretiva 2010/75/UE de 24 de novembro de 2010, relativa às emissões industriais.
} 


\subsection{Lições a tirar quanto à frequência de atitudes autoritárias e pouco democráticas}

Atitudes autoritárias, pouco democráticas, sem cultura de participação nem de respeito por direitos humanos, da parte da administração pública, dos governos e até dos tribunais nacionais são a regra, e não a exceção, nos casos que chegam ao Tribunal Europeu. Uma leitura atenta dos argumentos da defesa nos casos analisados mostra atitudes prepotentes (caso Hatton c. Reino Unido, 2003; Flamenbeaum c. França, 2013), formalistas (caso Dubetska c. Ucrânia, 2011) e de desconsideração pura e simples dos direitos humanos (caso Fadeyeva c. Rússia, 2005).

Estes casos revelam a importância de levar a sério os deveres da Convenção de Aarhus, a necessidade de capacitar a administração pública para o respeito dos direitos fundamentais, tal como previsto no artigo $10^{\circ}$ do Acordo Regional sobre Acesso à Informação, Participação Pública e Acesso à Justiça em Assuntos Ambientais na América Latina e no Caribe ${ }^{20}$. A referida norma, tão necessária no continente sul-americano como no europeu, visa o "fortalecimento de capacidades", e estabelece um conjunto de medidas que deverão ser adotadas, pelos Estados signatários, com vista a consciencializar e capacitar as autoridades, os agentes públicos judiciais e administrativos, as instituições nacionais de direitos humanos e os juristas, sobre o direito ambiental e os direitos de acesso $^{21}$.

\section{O FUTURO DO DIREITO À HABITAÇÃO}

Qual poderá ser, no futuro, a evolução jurisprudencial que assegure ao Tribunal Europeu dos Direitos do Homem um lugar de destaque como órgão jurisdicional enquadrado no seu tempo, bastião da proteção judicial dos direitos humanos no século XXI, que desenvolve de uma interpretação dinâmica e não estagnada do Direito, num tempo de transição ecológica ${ }^{22}$ em que o imperativo ambiental e climático é "a maior ameaça sistémica global" 23 que a humanidade alguma vez enfrentou?

Vamos apontar duas vias possíveis de evolução: a primeira, é a ampliação das formas de degradação ambiental relevante; a segunda decorre de um novo olhar sobre a opção de realojamento $^{24}$ das vítimas.

\footnotetext{
20 A denominada Convenção de Escatzu, assinada em 2018 na Costa Rica.

${ }^{21}$ Artigo 10 : "1. A fim de contribuir para a implementação das disposições do presente Acordo, cada Parte comprometese a criar e fortalecer as capacidades nacionais, com base em suas prioridades e necessidades. 2. Cada Parte, de acordo com as suas capacidades, poderá tomar, entre outras, as seguintes medidas: a) formar e capacitar autoridades e agentes públicos nos direitos de acesso sobre questões ambientais; b) desenvolver e fortalecer programas de conscientização e criação de capacidades em direito ambiental e direitos de acesso para o público, agentes judiciais e administrativos, instituições nacionais de direitos humanos e juristas, entre outros; c) dotar as instituições e os organismos competentes de equipamentos e recursos adequados; d) promover a educação, a capacitação e a conscientização sobre questões ambientais mediante, entre outros meios, a inclusão de módulos educativos básicos sobre os direitos de acesso para estudantes em todos os níveis educacionais; e) contar com medidas específicas para pessoas ou grupos em situação de vulnerabilidade, como a interpretação ou tradução em idiomas distintos do oficial, se necessário; f) reconhecer a importância das associações, das organizações e dos grupos que contribuem para formar ou conscientizar o público sobre os direitos de acesso; g) fortalecer as capacidades para coletar, manter e avaliar informação ambiental".

${ }^{22}$ François Collart Dutilleul, Valérie Pironon e Agathe Van Lang, Dictionnaire Juridique des Transitions Écologiques, Varenne, 2018.

${ }^{23}$ Palavras do Secretário Geral das Nações Unidas na intervenção no Fórum Económico Mundial, em 25 de janeiro de 2019, em Davos (https://unfccc.int/news/antonio-guterres-climate-change-is-biggest-threat-to-global-economy).

24 "Resettlement", na expressão original, em língua inglesa.
} 


\subsection{Da poluição do ambiente, à degradação ecológica}

A evolução jurisprudencial futura poderá ir no sentido de considerar um segundo tipo de ingerências no direito a usufruir da habitação. Além das pacificamente reconhecidas ingerências associadas a emissões poluentes, reconhecer igualmente como ingerência, a degradação grave das condições ecológicas no entorno da habitação, pode representar um passo em frente na proteção efetiva do direito humano à habitação.

Não há dúvida de que as emissões poluentes, que se propagam pelo ar, pela água, pelo solo ou pela biodiversidade e que transformam um local aprazível — saudável, silencioso e sem cheiros - num local inabitável — doentio, ensurdecedor e pestilento configuram, uma perturbação insuportável do direito a usufruir da habitação.

Diferentemente, as degradações ecológicas são o efeito principal e necessário de atividades que alteram significativamente as condições ecológicas do entorno da habitação, transformando um ambiente ameno, reconfortante e estimulante, num ambiente árido, desolador e depressivo.

As atividades que estão na origem de emissões que degradam o ambiente e violam o direito humano à habitação, são atividades industriais de transformação, atividades extrativas, atividades de transporte intensivo, ou até atividades de lazer.

No futuro, as atividades económicas que provocam degradação ecológica, de tal modo grave que deve ser considerada como violadora do direito humano à habitação, podem ser, por exemplo:

- atividades de urbanização, de construção de vias de comunicação ou outras infraestruturas, que levam à destruição sistemática da cobertura vegetal de toda uma região, ou que obrigam à drenagem de zonas húmidas, transformadas em lúgubres selvas de betão;

- atividades de extração de massas minerais, que levam ao arrasamento de paisagens rústicas, transformadas em cenários ermos e inertes;

- intervenções destinadas à irrigação agrícola ou à produção de energia, com desvios massivos de rios (mega-transvases) ou bloqueios colossais de cursos de água (mega-barragens), profundamente disruptivas da biodiversidade e do equilíbrio hidrológico.

As atividades descritas, e outras similares, causam degradação ambiental profunda, transformando negativamente o ambiente e convertendo os moradores em vítimas humanas, cujas condições de desfrutar da sua habitação se perdem, cuja qualidade de vida se esfuma, cuja saúde, física e psicológica, se deteriora.

Situações como estas não são inéditas no Tribunal Europeu dos Direitos do Homem, e até já deram aso a uma opinião profundamente dissidente do juiz italiano, Vladimiro Zagrebelsky, no caso Kyrtatos c. Grécia, de 2003, a propósito da destruição sistemática de uma zona húmida importante para conservação da natureza e a proteção de espécies selvagens, tal como previsto na constituição grega ${ }^{25}$.

${ }^{25}$ Pela sua expressividade, convicção e eloquência, vale a pena acompanhar a argumentação desenvolvida, nas próprias palavras do juiz: «Votei contra a conclusão da maioria, que considerou não ter havido violação do artigo $8 .^{\circ}$ da Convenção. Com pesar, não pude seguir o raciocínio que convenceu a maioria dos juízes a excluir a declaração de qualquer violação da vida privada das recorrentes.

Não há dúvida de que o meio ambiente não é protegido como tal pela Convenção. Mas, ao mesmo tempo, não há dúvida de que uma degradação do meio ambiente poderia equivaler a uma violação de um direito específico reconhecido pela 
Perante um ponto de inflexão interpretativa ${ }^{26}$, a questão que deve ser colocada é a de saber se o entendimento proposto comportará o risco de abrir uma caixa de Pandora. A resposta deve ser negativa, pois pensamos que aceitar um conceito mais amplo de intromissões na habitação, não significa aceitar que quaisquer degradações das condições ecológicas no entorno da habitação constituam imediatamente uma violação de direitos fundamentais. Tal como acontecia nos casos de poluição consensualmente aceites, só acima de um certo nível de emissões (em termos de intensidade e de duração) se poderia considerar estar perante uma violação de direitos humanos. De igual forma, apenas as atividades destruidoras da natureza que assumam um nível elevado de gravidade, é que configurarão uma ingerência inadmissível no direito humano à habitação.

Assim, tal como para a avaliação da gravidade da poluição, a uma avaliação objetiva (expressa em decibéis, miligramas ou outras unidades de medida), deve juntar-se uma valoração subjetiva, considerando como a situação concreta da vítima (idade, estado de saúde, tempo de permanência em casa) pode influenciar a determinação da gravidade do caso sub iudice. Deste modo, no caso da avaliação da degradação ecológica também devemos proceder a uma avaliação objetiva, a par de uma avaliação subjetiva.

Alguns dos critérios a ter em consideração na avaliação objetiva da gravidade são: a extensão geográfica da degradação, o número de exemplares de um espécie vegetal ou de animais mortos, a reversibilidade ou irreversibilidade do dano à escala da vida humana, ou o próprio estatuto jurídico do local: ser ou não um habitat classificado à luz de regimes jurídicos de proteção internacional ou europeia — como a convenção de Ramsar, de Bona, ou a Rede Natura 2000

Convenção (...). No presente caso, é claro que houve uma deterioração na qualidade do meio que a casa dos requerentes estava situada. Em particular, é indiscutível que o novo desenvolvimento urbano causou danos ao habitat da fauna que tornou a área pantanosa próxima à propriedade dos requerentes perto da costa de Ayios Yiannis, excepcionalmente interessante e agradável.

Na minha opinião, dificilmente se poderia dizer que a deterioração do ambiente não conduzia a uma correspondente deterioração da qualidade de vida dos requerentes, mesmo sem ter em conta o seu especial interesse no estudo da fauna do pântano.

Obviamente, é difícil quantificar os danos causados à qualidade de vida privada e familiar dos requerentes. Mas a questão aqui é saber se houve ou não uma ingerência, e não quão séria a ingerência foi. Certamente, devemos excluir a constatação de qualquer interferência nos direitos dos recorrentes se a deterioração em causa for tão insignificante que é praticamente inexistente. Na minha opinião, porém, não foi esse o caso. No parágrafo 53, a maioria aceita, a título de exemplo, que a destruição de uma floresta que faz fronteira com a casa dos requerentes poderia constituir uma ingerência direta na vida privada e familiar, para os fins do Artigo 8 da Convenção. Concordo, mas não vejo grande diferença entre a destruição de uma floresta e a destruição do extraordinário ambiente pantanoso de que os requerentes poderiam desfrutar perto de sua casa.

Estou disposto a admitir que a interferência em questão não foi importante, mas, a meu ver, é impossível dizer que não houve interferência alguma. É verdade que a importância da qualidade do meio ambiente e a crescente consciencialização dessa questão não podem levar o Tribunal a ir além do escopo da Convenção. Mas esses fatores devem induzir a reconhecer a crescente importância da deterioração ambiental na vida das pessoas. Tal abordagem estaria perfeitamente de acordo com a interpretação dinâmica e a atualização evolutiva da Convenção, que o Tribunal atualmente adota em muitas áreas.

$\mathrm{O}$ artigo $8^{\circ}$ permite até mesmo sérias e graves ingerências do Estado no direito à vida privada e familiar. No entanto, uma ingerência infringirá o Artigo $8^{\circ}$, a menos que esteja "de acordo com a lei", prossiga uma ou mais das metas legítimas mencionadas no parágrafo 2 e seja necessária para alcançá-las "numa sociedade democrática". No presente caso, não é necessário examinar se a ingerência no direito das recorrentes era necessária e proporcionada aos interesses económicos concorrentes. Aqui o Tribunal tinha apenas de verificar que, tal como os tribunais gregos decidiram, a ingerência era ilegal. Assim, a primeira condição básica para a legitimidade, até mesmo de uma pequena interferência na vida privada ou familiar não foi cumprida.

Portanto, penso que o Tribunal deveria ter declarado uma violação do artigo 8 da Convenção».

${ }^{26}$ Adotando igualmente uma posição critica relativamente ao não reconhecimento, pelo Tribunal Europeu, da existência de uma violação do artigo $8^{\circ}$, Alan Boyle ("Human Rights or Environmental Rights? A Reassessment", Fordham Environmental Law Review Vol. 18, No. 3, Symposium: Environmental Protection and Human Rights in the New Millennium: Perspectives, Challenges, and Opportunities, 2007, p. 471-511). 
Europeia — ou um regime jurídico de proteção nacional como a Rede Nacional de áreas de Proteção, em Portugal.

Quanto à avaliação subjetiva da gravidade, consideramos como incontornável a utilização dos conceitos desenvolvidos no âmbito da teoria dos serviços dos ecossistemas ${ }^{27}$ que, pelo seu caráter explicativo $^{28}$, permitem uma apreciação, de uma forma cientificamente neutra, do valor humano dos ecossistemas, permitindo decifrar, com um grau aceitável de segurança, o grau de perda que uma determinada degradação ecológica representa para uma pessoa, uma família ou uma comunidade. Com efeito, a perda subjetiva depende dos tipos de benefícios individuais de que o cidadão em causa usufruía, e que, pela degradação, deixou ou deixará de usufruir. Tais benefícios podem ser reconduzidos a um conjunto de categorias e subcategorias estabilizadas atualmente pelo trabalho conjunto de desenvolvimento das Nações Unidas e da União Europeia $^{29}$.

Ilustrativamente, se pensarmos em comunidades piscatórias, que residem ao lado de um curso de água, de onde retiram o seu sustento, a construção de uma barragem ${ }^{30}$ e a consequente redução ou desaparição dos peixes, significa, para essa comunidade, a privação da sua fonte principal de alimento e subsistência. Na linguagem dos serviços dos ecossistemas, isso significa que perderam serviços de provisão.

Diferentemente, se quem residia ao lado do curso de água, onde foi instalada a barragem que levou à desaparição dos peixes, era um pescador desportivo, que dedicava os seus tempos livres à pesca, aquilo que se perdeu foi uma oportunidade de lazer ou, na linguagem dos serviços ecossistémicos, perdeu serviços recreativos.

Noutro exemplo, se alguém reside junto a um bosque, onde a sua família sempre residiu, que usa para caçar e recolher espécies micológicas, e extrair lenha para aquecimento, o abate de todas as árvores para produção de celulose para a indústria do papel significa, além do risco de fome e frio, também a perda do sentido de pertença ao local. Em linguagem técnica, dos serviços dos ecossistemas, perdeu serviços de provisão e serviços identitários.

Se, pelo contrário, quem foi afetado pela ação de desflorestação era um especialista em botânica e estudioso de espécies florestais, o corte de todas as árvores constitui o fim do seu objeto de estudo e de produção científica. Na linguagem dos serviços dos ecossistemas, significa que perdeu serviços culturais científicos ou educativos.

Por outras palavras, em função do diferente uso da natureza, as perdas resultantes da degradação ecológica são também diversas: podem representar perdas de caráter individual ou coletivo, de caráter essencial ou acessório. Pode ser afetada a possibilidade de satisfazer necessidades fisiológicas vitais, como alimentação ou aquecimento, ou necessidades espirituais e imateriais, como meditação ou convívio. Estas últimas, aparentemente menos importantes na hierarquia da essencialidade à vida, podem, in casu, ser igualmente reputadas de caráter existencial,

27 Alexandra Aragão, "A natureza não tem preço... mas devia. O dever de valorar e pagar os serviços dos ecossistemas" in: Estudos em homenagem a Jorge Miranda, Coimbra Editora, 2012, vol. IV, p. 11 a 41.

${ }^{28} \mathrm{Na}$ União Europeia o conceito já com consagração legal através da Diretiva 2004/35 de 21 de abril, relativa à responsabilidade ambiental em termos de prevenção e reparação de danos ambientais, que define dano como "a alteração adversa mensurável, de um recurso natural ou a deterioração mensurável do serviço de um recurso natural (...)" (artigo $2^{\circ} \mathrm{n}^{\circ}$ 2, itálico nosso).

29 A Divisão de Estatística das Nações Unidas está a trabalhar em conjunto com a Agência Europeia do Ambiente para desenvolver uma Classificação Internacional Comum de Serviços dos Ecossistemas (CICES) para fins de contabilidade ambiental (a versão mais atualizada, está disponível em https://cices.eu/).

${ }^{30}$ É discutível se medidas de minimização, como escadas de peixes, permitem mitigar os efeitos do obstáculo (sobretudo tratando-se de um paredão de cimento de centenas de metros de altura) na capacidade migratória dos peixes para a desova. 
nomeadamente por serem ligadas à identidade pessoal ou coletiva. É por isso que a gravidade só pode ser aferida em concreto, em função de uma análise científica da força e da importância dos elos de ligação entre a pessoa e a natureza ${ }^{31}$.

\subsection{Do realojamento, ao dever de prevenção de deslocados ambientais internos}

Futuramente, $\mathrm{o}$ artigo $8^{\circ}$ poderá vir a ser utilizado para colmatar uma grave lacuna jurídica de proteção nos tempos atuais: a defesa dos deslocados ambientais ${ }^{32}$.

Fazendo, antes de mais, o ponto da situação sobre a forma como os recorrentes, as autoridades nacionais e o Tribunal Europeu lidam com a questão do deslocamento das vítimas, verificamos seis situações diferentes:

- Casos em que as autoridades assumem a obrigação e o encargo do realojamento das vítimas (caso Lopez Ostra 1994, realojamento num apartamento a cargo do Município mas sem condições, e no qual as vítimas não conseguiram permanecer; caso Giacomelli c. Itália 2007, realojamento temporário, na pendência da decisão judicial).

- Casos em que, apesar de as autoridades afirmarem assumir o realojamento das vítimas, ou condenarem a empresa poluidora a fazê-lo, tal nunca vem a ocorrer (caso Fadeyeva c. Rússia, de 2005, as vítimas são postas na lista de pessoas para realojamento em 1999 ficando com o $\mathrm{n}^{\circ} 6820$, e sabendo que o primeiro colocado na mesma lista está à espera desde 1968, ou seja há 31 anos; caso Dubetska c. Ucrânia, de 2011, com promessa pública de realojamento por conta da empresa desde 1994, mas nunca concretizada).

- Casos em que as autoridades oferecem oportunidades de realojamento às vítimas, que recusam sistematicamente aceitar residir noutro local (caso Dzemyuk c. Ucrânia, de 2014, no qual os residentes ao lado do cemitério ilegal se recusam a abandonar a casa onde sempre residiram).

- Casos em que as vítimas assumem, elas próprias, a decisão de se deslocar para outro local de residência (caso Hatton c. Reino Unido, de 2003; caso Tatar c. Roménia, de 2009; caso Milleva c. Bulgária, de 2011).

- Casos em que as vítimas não conseguem abandonar o local de residência, em virtude da desvalorização do imóvel (casos Apanasewicz c. Polónia, 2011; Flamenbeaum c. França, 2013; Fagerskiold c. Suécia, 2008; Dubetska c. Ucrânia, 2011) ou então porque só têm condições económicas para residir naquele imóvel, cujas rendas são substancialmente mais baixas (caso Fadeyeva c. Rússia, 2005).

- Casos em que as vítimas não abandonam o local de residência, mas pedem uma compensação judicial pela desvalorização do imóvel em virtude da ingerência ambiental (caso Bor c. Hungria, 2013).

${ }^{31}$ Um exemplo de um estudo científico desta ligação enquadra-se no âmbito da avaliação dos ecossistemas do milénio e foi coordenado por McMichael, Anthony e Scholes, Robert, Ecosystems and Human Well-being. A framework for assessments. Chapter 3: Linking Ecosystem Services and Human Well-being.

32 Internal Displacement Monitoring Centre e Norwegian Refugee Council, Global Report on Internal Displacement, Genebra, 2017. 
Apesar de, nos acórdãos citados, os Estados recorridos invocarem que o cidadão é livre de se deslocar, afastando-se da fonte poluente, e apesar de o próprio Tribunal Europeu aceitar a solução de "resettlement" garantido pelo Estado ou pela empresa poluente, como uma solução aceitável (Dubetska c. Ucrânia, 2011) para um problema ambiental, que está na origem de ingerências arbitrárias na habitação, não podemos agir como se as habitações fossem bens fungíveis, intercambiáveis sem qualquer consequência. É precisamente no acórdão Dubetska c. Ucrânia, de 2011, que os recorrentes falam da perturbação da vida familiar resultante da degradação das condições ambientais da habitação: marido e mulher passam a ter uma relação conflituosa, os filhos mais velhos ausentam-se porque não querem criar os seus próprios filhos num ambiente tão pouco saudável.

Além da perda da ligação familiar, visível neste caso, noutros, é a dimensão identitária do local que é considerada mais relevante (Fagerskiold c. Suécia, de 2008).

Por isso o afastamento forçado da habitação é uma violação particularmente grave de direitos humanos ${ }^{33}$ pelo que pode significar de perda de laços familiares e redes informais de apoio social, desenraizamento cultural e perda de referências identitárias ${ }^{34}$.

A partir do momento em que o Tribunal deu o primeiro passo, e considerou certas perturbações ambientais graves como ingerências abusivas no domicílio, nem sequer é preciso uma grande construção jurídica para permitir o recurso ao artigo $8^{\circ}$ enquanto mecanismo de proteção dos deslocados ambientais. Quando as vítimas de ingerências ambientais, de tal modo agudas que impedem a permanência na habitação, se vêem-se forçadas a abandonar a sua casa e a procurar um novo local de residência, materialmente estamos perante deslocados ambientais.

De facto, o âmbito da proteção jurídica ao domicílio abrange o direito a usufruir da habitação e a permanecer nela, sem ingerências externas que o tornem inabitável (expressão usada recorrentemente no caso Dees c. Hungria, de 2011) e que obriguem as vítimas a abandonar o local, com o desenraizamento que uma deslocação forçada sempre acarreta.

Em termos de responsabilização do Estado, o dever de proteger os deslocados ambientais, tratando-se de deslocados internos, é um dever sucedâneo de proteção da habitação que decorre de não ter cumprido o dever principal de não efetuar nem tolerar ingerências ambientais graves na habitação.

Que obrigações integram este dever de proteção? Pelo menos a obrigação de encontrar um local de acolhimento provisório com condições mínimas de habitabilidade e, sendo possível, a obrigação de apurar as causas daquela situação de tomar as medidas eficazes e necessárias para que não se repita e proceder à requalificação, tão rapidamente quanto seja praticável, da habitação, a fim de permitir, querendo, o retorno dos deslocados. Não sendo possível, ou havendo razões ponderosas para não voltar (nomeadamente a manutenção de níveis de risco elevados, como aconteceria tratando-se de situação de contaminação do solo por metais pesados, muito difícil de reverter) incumbirá ao Estado encontrar um local de acolhimento definitivo, em condições pelo menos equivalentes.

${ }^{33}$ Camillo Boano, Roger Zetter, Tim Morris, Environmentally displaced people. Understanding the linkages between environmental change, livelihoods and forced migration, Refugee Studies Centre, Oxford Department of International Development, University of Oxford, 2008 (disponível em https://www.rsc.ox.ac.uk/files/files-1/pb1-environmentallydisplaced-people-2008.pdf)

${ }_{34}$ Roger Zetter, Protecting environmentally displaced people. Developing the capacity of legal and normative frameworks, Refugee Studies Centre, Oxford Department of International Development, University of Oxford, 2011 (disponível em https://www.refworld.org/pdfid/4da579792.pdf). 
Este é no estádio atual de desenvolvimento do Direito, o regime jurídico mínimo de proteção dos deslocados ambientais, sempre que se trate de deslocados internos.

Apesar de a figura dos deslocados ambientais não se confundir com os refugiados em sentido tradicional ${ }^{35}$, há alguns elementos em comum que justificam a comparação. Nos casos de violação do direito ambiental à habitação, verifica-se também o elemento material do direito de asilo: a inexigibilidade da permanência e a inevitabilidade da fuga do local de residência habitual que se tornou inabitável. Falta, naturalmente, o elemento subjetivo: a intenção persecutória relativamente a uma pessoa, uma família ou um grupo social, em virtude de características que lhe são próprias, como nacionalidade, religião, raça, ideologia, orientação sexual ou outras.

No entanto, a intensificação da frequência dos movimentos de pessoas por razões ambientais justifica e torna cada vez mais premente a necessidade de desenvolver um novo regime jurídico internacional para os deslocados ambientais e climáticos, aos quais não é aplicável o regime jurídico dos refugiados. Enquanto esse regime não surge, a proteção dos deslocados ambientais internos através do artigo $8^{\circ}$ da CEDH revela outra abordagem possível do mesmo problema. Perante o flagelo humanitário do Século XXI — o movimento migratório ambiental forçado - em vez de a intervenção do ordenamento jurídico internacional se dar a jusante, exigindo do Estado de acolhimento um nível mínimo de proteção, o ordenamento jurídico internacional pode intervir a montante, exigindo do Estado de origem a rápida mitigação da degradação ambiental e recuperação das condições de habitabilidade perdidas, assegurando condições para o regresso. Por outras palavras, exige-se do Estado de origem a garantia do respeito do direito à habitação. Com exceção dos casos em que a catástrofe ambiental tenha causado uma disrupção grave a nível do país, que impeça o Estado de tomar quaisquer medidas, como no caso de um grave acidente nuclear, por exemplo, cabe antes de mais ao Estado de origem, adotar as medidas adequadas para permitir o retorno dos deslocados.

Neste sentido, o dever de proteger o direito humano ao domicílio, consagrado na Convenção Europeia dos Direitos do homem tem o efeito prático de evitar a desterritorialização ${ }^{36}$ resultante do afastamento da habitação, e ao mesmo tempo de prevenir a ocorrência de deslocados ambientais internacionais.

Atualmente, considerando a emergência internacional da figura dos deslocados ambientais ${ }^{37}$, a norma do artigo $8^{\circ}$ deve ser lida como incluindo o direito de o cidadão escolher a sua habitação em função dos seus interesses ou das suas possibilidades económicas, e de nele permanecer, não podendo ser forçado a conformar-se com a degradação nem refugiar-se noutro local onde as condições de vida sejam menos insalubres.

\section{CONCLUSÃO: A PROTEÇÃO AMBIENTAL NO CONSELHO EUROPEU}

Com efeito, há décadas que a Convenção dos Direitos do Homem já deveria ter reconhecido explicitamente o direito humano ao ambiente. Em vista da manifesta necessidade de manter a Convenção como "instrumento vivo", o Tribunal Europeu dos Direitos do Homem passou a

\footnotetext{
35 Protegidos pela Convenção das Nações Unidas de 1951, relativa ao estatuto dos refugiados, alterada pelo Protocolo de Nova Iorque, de 31 de janeiro de 1967.

${ }^{36}$ Sobre o conceito de "desterritorialização" ver Rogério Haesbaert, Da Desterritorialização à Multiterritorialidade, Boletim Gaúcho de Geografia, n. ${ }^{\circ}$ 29, janeiro de 2003, páginas 11 a 24.

${ }^{37}$ Alto Comissariado das Nações Unidas para os Refugiados, Guiding Principles on Internal Displacement, New York, 2001.
} 
utilizar os meios de proteção jurídica indireta ao seu dispor para garantir as condições ambientais de vida nomeadamente por meio do direito à habitação.

Nesse contexto, a jurisprudência do Tribunal Europeu dos Direitos do Homem demonstra a importância da disponibilidade de mecanismos de tutela coletiva que facilitem o acesso à justiça; a relevância, ao nível interno, da existência de normas e mecanismos de proteção jurídica mais céleres; a ponderação da necessidade de manter em funcionamento atividades consabidamente nocivas em determinadas regiões; e a utilidade de capacitar a administração pública para respeito dos direitos fundamentais.

Este estudo jurisprudencial permite extrair duas possíveis vias de evolução: a primeira é o reconhecimento, como ingerência inadmissível, da degradação grave das condições ecológicas no entorno da habitação; a segunda decorre de um novo olhar sobre o artigo $8^{\circ}$ da Convenção Europeia, garantindo ao cidadão o direito de escolher a sua habitação em função de seus interesses ou de suas possibilidades econômicas.

\section{REFERÊNCIAS}

ARAGÃO, Alexandra “A natureza não tem preço... mas devia. O dever de valorar e pagar os serviços dos ecossistemas" in: Estudos em homenagem a Jorge Miranda, Coimbra Editora, 2012, vol. IV, p. 11 a 41.

ARAGÃO, Alexandra; CARVALHO, Ana Celeste "Taking access to justice seriously: diffuse interests and actio popularis. Why not?" in: ELNI Review, Environmental Law Network International, $\mathrm{n}^{\mathrm{o}}$ 2/2017, pp. 42-48.

BOANO, Camillo; ZETTER, Roger; MORRIS, Tim Environmentally displaced people. Understanding the linkages between environmental change, livelihoods and forced migration, Refugee Studies Centre, Oxford Department of International Development, University of Oxford, 2008 (Disponível em: https://www.rsc.ox.ac.uk/files/files-1/pb1-environmentally-displaced-people-2008.pdf).

BOSSELMANN, Klaus When two worlds collide: society and ecology, RSVP Publishing Company Limited, 1995.

BOYLE, Alan ("Human Rights or Environmental Rights? A Reassessment", Fordham Environmental Law Review Vol. 18, No. 3, Symposium: Environmental Protection and Human Rights in the New Millennium: Perspectives, Challenges, and Opportunities, 2007, p. 471-511, Disponível em: https://ir.lawnet.fordham.edu/cgi/viewcontent.cgi?article=1634\&context=elr).

CARSON, Rachel Silent Spring, Houghton Mifflin, 1962.

COUNCIL OF EUROPE, Manual on Human Rights and the Environment, Strasbourg, 2012.

COUNCIL OF EUROPE, Parliamentary Assembly Recommendation 1431 (1999), "Future action to be taken by the Council of Europe in the field of environment protection" (Disponível em: http://assembly.coe.int/nw/xml/XRef/Xref-DocDetails-en.asp?FileID=16731\&lang=en).

DUTILLEUL, François Collart; Pironon, Valérie; Van Lang, Agathe Dictionnaire Juridique des Transitions Écologiques, Varenne, 2018.

GLAZEBROOK, Susan "Human Rights and the environment", Victoria University of Wellington Law Review, vol. 40 n. 1 June 2009, p. 293 (Disponível em: https://courtsofnz.govt.nz/ speechpapers/Human\%20Rights\%20and\%20the\%20Environment.pdf). 
HAESBAERT, Rogério "Da Desterritorialização à Multiterritorialidade", Boletim Gaúcho de Geografia, n. ${ }^{\text {o } 29}$, janeiro de 2003, páginas 11 a 24. (Disponível em: https://seer.ufrgs.br/bgg/ article/view/38739/26249).

INTERNAL DISPLACEMENT MONITORING CENTRE; NORWEGIAN REFUGEE COUNCIL, Global Report on Internal Displacement, Genebra, 2017 (Disponível em: http://www.internal-displacement.org/global-report/grid2017/).

MCMICHAEL, Anthony; SCHOLES, Robert, Ecosystems and Human Well-being. A framework for assessments. Chapter 3: Linking Ecosystem Services and Human Well-being, (Disponível em: https://www.millenniumassessment.org/documents/document.341.aspx.pdf).

OST, François A Natureza à Margem da Lei. A ecologia à prova do Direito, Piaget, 1998.

PEDERSEN, Ole "Environmental principles and the European Court of Human Rights" in Ludwig Kramer and Emanuela Orlando (eds), Principles of Environmental Law, Elgar Encyclopedia of Environmental Law (Edward Elgar) vol VI, 2018, p. 578-586, (também Disponível em: https://papers.ssrn.com/sol3/papers.cfm?abstract_id=3179420).

REMOND-GOUILLOUD, Martine Du droit de détruire : éssai sur le droit de l'environnement, Presses Universitaires de France, 1989.

SANTOS, Boaventura de Sousa "Poderá o Direito ser emancipatório?" Revista Crítica de Ciências Sociais, n. ${ }^{\circ} 65$, maio de 2003, 3-37.

SHELTON, Dinah «Developing Substantive Environmental Rights», 1 Journal of Human Rights \& Environment, March 2010, p. 89-120.

UNITED NATIONS, High Commissioner for Refugees, Guiding Principles on Internal Displacement, New York, 2001 (Disponível em: https://www.unhcr.org/protection/idps/43ce1cff2/ guiding-principles-internal-displacement.html).

ZETTER, Roger Protecting environmentally displaced people. Developing the capacity of legal and normative frameworks, Refugee Studies Centre, Oxford Department of International Development, University of Oxford, 2011 (Disponível em: https://www.refworld.org/pdfid/ 4da579792.pdf).

\section{Instrumentos normativos}

Convenção das Nações Unidas de 1951, relativa ao estatuto dos refugiados, alterada pelo Protocolo de Nova Iorque, de 1967.

Convenção de Aarhus sobre Acesso à Informação, Participação do público no processo de tomada de decisão e Acesso à Justiça em Matéria de Ambiente, de 1998

Convenção de Escatzu sobre Acesso à Informação, Participação Pública e Acesso à Justiça em Assuntos Ambientais na América Latina e no Caribe de 2018

Decisão 2019/435 da Comissão Europeia, de 12 de março de 2019 sobre a proposta de iniciativa de cidadania intitulada «Habitação para todos».

Diretiva 2004/35 de 21 de abril, relativa à responsabilidade ambiental em termos de prevenção e reparação de danos ambientais

Diretiva 2010/75/UE de 24 de novembro de 2010, relativa às emissões industriais 


\section{Jurisprudência}

Tribunal Europeu dos Direitos do Homem. Hatton and others v. The United Kingdom, n. 36022/97, 8 de julho de 2003

Tribunal Europeu dos Direitos do Homem. Kyrtatos v. Greece, n. 41666/98 22, de maio de 2003

Tribunal Europeu dos Direitos do Homem. Tătar c. Roumanie, n. 67021/01, 27 de janeiro de 2009

Recebido em: 14 mar. 2020.

Aceito em: 27 out. 2020. 